\title{
EL PROYECTO CRISTIANO DE LOS EMPERADORES MAURICIO Y HERACLIO EN LA HISTORIA DE TEOFILACTO SIMOCATTA: CONSIDERACIONES SOBRE LA NARRACIÓN Y SU PROPÓSITO
}

\author{
DANIEL NIETO ORRIOLS \\ UNIVERSIDAD ANDRÉS BELLO. Chile
}

\begin{abstract}
Resumen: En el presente trabajo se analiza la imagen del Imperio Romano en la Historia de Teofilacto Simocatta. En esta se identifica el uso de recursos narrativos que destacan a los emperadores Mauricio y Heraclio con un proyecto imperial cristiano común, exhibiendo virtudes y actitudes que el autor promueve a imitar y consolidar bajo su concepción escatológica y ecuménica.
\end{abstract}

Palabras clave: Teofilacto, Emperador Mauricio, Heraclio, Focas, escatología, Bizancio.

\section{THE CHRISTIAN PROJECT OF EMPERORS MAURICE AND HERACLIUS IN THE HISTORY OF THEOPHYLACT SIMOCATTA: CONSIDERATIONS ON THE NARRATION AND ITS PURPOSE}

\begin{abstract}
In the following paper the image of the Roman Empire is analyzed in the History of Theophylact Simocatta. In this, we note the use of narrative resources that highlight the Mauritius Emperor and Heraclius with a common Christian emperor's imperial project, exhibiting virtues and attitudes that the author promotes role and consolidate under its eschatological and ecumenical conception.
\end{abstract}

Keywords: Theophylact, Emperor Maurice, Heraclius, Phocas, Escathology, Byzanthium.

Recibido: 22.01.2016 - Aceptado: 28.04.2016

Correspondencia: Daniel Nieto Orriols

Email: dnietoorriols@gmail.com daniel.nieto@unab.cl

Magister en Historia. Tesista Doctorado en Historia en la Pontificia Universidad Católica de Valparaíso. Viña del Mar. Teléfono: 322845531. 


\section{Introducción ${ }^{1}$}

aborda el reinado del Emperador Mauricio refiriendo, además, a los períodos de sus predecesores Justino II y Tiberio II y al de sus sucesores Focas y Heraclio. Su trabajo representa la mayor creación de la Tardoantigüedad sobre el Emperador Mauricio, y constituye la última obra historiográfica tardoantigua de estilo clasicista 4 .

Este tipo de historias centran su atención, preferentemente, en los episodios políticos, diplomáticos y militares ${ }^{5}$, y la Historia no es la excepción. Tratando el devenir del Imperio Romano -Bizantino- entre los años 582 y 602, alude a los conflictos político-militares en sus fronteras oriental, balcánica y danubiana, poniendo énfasis en los encuentros diplomáticos romanos, donde destaca la inclusión de extensos discursos ${ }^{6}$; de modo que nos presenta un cuadro histórico general de la época del Emperador Mauricio y de los encuentros de Roma con los pueblos persa, eslavo y ávaro.

Aun cuando el historiador distingue y enaltece la figura del Emperador Mauricio, no explica los motivos que lo llevaron a escribir su historia ${ }^{7}$, omisión

$\overline{1}$ El presente artículo es resultado del seminario de investigación a cargo del Dr. José Marín en el Doctorado en Historia de la Pontificia Universidad Católica de Valparaíso.

2 Según Whitby, las obras de Teofilacto las podemos dividir en mayor: la Historia, y menores. Entre las últimas: sus Natural Questions y sus Ethical Epistles, según Whitby bien conocidas. De reciente edición y discusión: Predestined Terms of Life. Véase Whitby, 2002, pp. 33-34.

3 Para esta investigación hemos trabajado con la traducción al inglés de Michael and Mary Whitby (1986), The History of Theophylact Simocatta, Oxford University Press, Nueva York.

4 Balmaceda, 2013, p. 86.

$5 \quad$ Signes Codoñer, 2003, p. 129.

6 Los encuentros diplomáticos mediante embajadas las encontramos, en los siguientes libros: I, 3,1; 3,3; 3,6; 4,6; 6,2; 6,4-6; 8,7; 15,1; 15, 11-12. III, 2,2; 2,7; 2,9; $3,1-5 ; 6,14 ; 9,7 ; 10,9 ; 12,2-3 ; 15,5-7 ; 15,10 ; 17,1-2$. IV, 9, 5-6; 9,8; 12,3; 12,7-9; 14,2. V, 1,$3 ; 3,8-11$. VI, 2,12-14; 3,1; 3,5-6; 3,6-8; 6,6; 10,9; 11,4; 11,7-9. VII, 4,2; 4,6; 7,3$5 ; 7,7-8 ; 11,9 ; 13,3 ; 13,5-7 ; 13,9 ; 15,8-12$. VIII, 1,3-8; 1,9-10; 4,1-2; 6,9; 7,1; 8,1.

$7 \quad$ Extraño en historiadores clasicistas y cristianos, que solían explicar sus intereses, aportes y datos personales en los prólogos, que, como apunta Marín, corresponden a textos que permiten establecer la relación entre el autor y la obra de forma anexa al texto. Marín, J., 2014, p. 532-533. En Teofilacto, no obstante la 
que ha suscitado diferentes interpretaciones ${ }^{8}$. Si bien no hay acuerdo sobre las motivaciones que llevaron a Teofilacto a escribir la historia del Emperador Mauricio, algunas características de su obra permiten vislumbrar que esta no se abstrajo de su contexto. Escrita bajo el reinado de Heraclio' ${ }^{9}$, la Historia construye una imagen del pasado reciente del Imperio Romano en función de los problemas, interpretaciones históricas y necesidades de su propia época, lo que nos permite identificar sus posibles intenciones a partir de los recursos narrativos utilizados para ello.

Desde esta perspectiva, nuestra intención es comprender el texto en su contexto y, de este modo, identificar la función de la obra en la época de Teofilacto. Después de todo, el texto historiográfico posee una intención que remite a su presente, pues, como apunta Aurell, "La historiografía codifica una realidad pasada para fusionarla con el presente"

Así, nuestro problema dice relación con la intencionalidad del escrito, la interpretación que el autor hace del devenir y la función que él mismo advierte en su obra, lo que nos permitirá aproximar respuestas a las preguntas: ¿por qué Teofilacto construye una imagen del Imperio Romano a partir del cristianismo, en lo que parece un refuerzo de esta idea en su época? ¿Por qué se remite a los eventos diplomáticos utilizando los discursos de embajadores para ello? ¿Qué función cumplen estos episodios y discursos en la visión de la historia de Teofilacto? ¿Qué intención política, cultural o religiosa pudo haber tenido en la escritura de su historia?

Aun cuando no hay acuerdo sobre las intenciones de Teofilacto, sí hay claridad respecto de la exaltación de la figura de Mauricio sobre Focas y sobre la utilidad que prestan los discursos en su obra: establecer la propia perspectiva del autor ${ }^{11}$. Desde esta perspectiva, nuestra aproximación a la fuente nos ha entregado algunas luces sobre el modo en que Teofilacto construye su relato, lo que nos ha permitido entrever su propósito y elucidar su sentido. En esta línea, identificamos que la narración no se organizó solo para enaltecer a los emperadores, sino para encomiar un proyecto cristiano común necesario de

existencia de un proemio, no aparece información explícita de sus objetivos, así como tampoco datos sobre sí mismo.

8 Véanse Balmaceda, 2013, pp. 84 y 86; Frendo, 1988, pp. 152-153; Scott, 2010, p. 252; Reinink, 2002, p. 83; Whitby, M., 2002, p. 30; Kaegy, 2003, p. 12; Signes Codoñer, p. 120.

9 Whitby, Michael y Whitby, Mary, 1986, p. 11.

10 Aurell, Jaume, 2006, p. 825.

11 Signes Codoñer, p. 129; Rohorbacher, 2002, p. 159. 
entender e imitar, para lo que utilizó recursos narrativos.

Así, nuestra propuesta señala que la Historia de Teofilacto propone destacar un proyecto imperial cristiano virtuoso, común entre los Emperadores Mauricio y Heraclio, y necesario para la consolidación de la Roma Aeterna, esto es, guía del cristianismo hasta el fin de los tiempos; para lo que utilizó tópicos narrativos que exaltan o denostan el período de cada emperador. Los recursos narrativos utilizados son, por un lado, los discursos diplomáticos, mediante los cuales construye una imagen de Bizancio a partir de virtudes y actitudes cristianas; y por otro, la intervención providencial o sobrenatural en el acontecer. Ambos recursos le permiten otorgar una atmósfera ${ }^{12}$ favorable o desfavorable al desarrollo del imperio cristiano que, ante la perspectiva escatológica de la época, era necesario fortalecer.

\section{Auge y decadencia en el reinado de Mauricio: del discurso al ánimo del relato}

Aunque Teofilacto no explicita su propósito, la repetición de los tópicos narrativos en el escrito permite denotar una atmósfera en el relato y una imagen del Imperio que, definida por el cristianismo ${ }^{13}$, se transforma en la medida que el Emperador Mauricio adquiere mayor notoriedad ${ }^{14}$. Estos tópicos, a nuestro parecer, constituyen los recursos argumentativos del autor.

El primer episodio en que el autor ofrece una imagen del Imperio debilitado y con ánimo desfavorable es al inicio de la narración. En ella nos da a conocer los primeros encuentros entre ávaros y romanos, en los que a causa de la toma de Sirmio, los primeros habrían enviado una embajada a los bizantinos para tratar la paz $^{15}$. El debilitamiento romano del momento conllevaría un

12 Por "atmósfera" entendemos el ambiente o estado anímico que engloba la narración de algunos episodios y que los integra bajo un clima común. Véase Barthes, 1977, pp. 81-84.

13 Respecto del cristianismo de Teofilacto, véase Liebeschuetz, 2003, pp. 216217.

14 Distinguimos cuatro etapas anímicas en que suceden los acontecimientos. Relacionadas al emperador Mauricio, tres: 1) cuando recién asume, con un ambiente es negativo por los problemas previos a su gobierno; 2) en el apogeo de su gobierno, de atmósfera favorable; 3 ) cuando decae, donde paulatinamente adquiere una connotación de pesadumbre hasta la toma del poder de Focas, en que se torna negativa. Referida a Heraclio, distinguimos la última, con ánimo positivo. Las etapas no son lineales ni progresivas en la narración, sino que se advierten en diversas partes, incluso fuera de la narración misma, en el Diálogo inicial y en el Proemio.

Teof. Sim., I, 3, 3. 
acuerdo que Teofilacto califica de "vergonzoso"16, donde los romanos deberían pagar anualmente 80.000 monedas de oro al Khan.

Aun cuando frente a una primera aproximación a la fuente parece una cifra de magnitud, lo que Teofilacto no menciona es que este tipo de tratados era común en el Imperio Bizantino, que a través de una amplia tradición en política exterior había consolidado prácticas diplomáticas que, mediante $\operatorname{pagos}^{17} \mathrm{y}$ concesiones de títulos ${ }^{18}$, lograban mantener la paz en sus fronteras ${ }^{19}$.

La omisión de Teofilacto se comprende bajo su propósito anímico-debilitador, lo que se aclara cuando advertimos que, avanzada la explicación, apunta que la toma de la ciudad habría sucedido poco tiempo antes de que el Emperador Mauricio ocupara el trono de César ${ }^{20}$.

Esta mención nos permite entrever que Teofilacto comienza el relato explicando que el imperio anterior a Mauricio se encontraba en principios de decadencia, frente a lo cual el nuevo emperador se presentaba como solución, disponiéndose al cuidado de los romanos ${ }^{21}$. Con esta ambientación establece un directo vínculo con Mauricio, quien se inscribe con supremacía luego de comenzadas las actividades político-militares. $\mathrm{Y}$ es en este escenario que Simocatta introduce discursos que complementan su idea de imperio cristiano, proponiendo una imagen de Bizancio en relación al desempeño de los diplomáticos ${ }^{22}$. Así ocurre con la primera embajada bajo el gobierno de Mauricio, cual es enviada a los ávaros para terminar la guerra del "acuerdo vergonzoso", donde el autor, definiendo a Roma por oposición, destaca la arrogancia con la
16 Teof. Sim., I, 3, 7.
17 Herrera, 1972, p. 185.
18 Ibid., p. 20.
19 Chrysos, 2005, p. 115; Blockley, 1985, pp. 62-74, esp. 62-63.
20 Teof. Sim. I, 3, 4.
21 Teof. Sim. I, 3, 4.

22 La relación entre el diplomático y el pueblo al que representa responde a la tradición romana republicana e imperial. Para la época republicana un embajador debía desenvolverse en función de cómo deseaba ser vista la sociedad que representaba, lo que implicaba una representatividad política y cultural. Esto se traspasó a Bizancio, donde los funcionarios imperiales se consideraban representantes del Emperador y del imperio como unidad. Por ello Teofilacto se refiere al carácter de los pueblos a través de sus diplomáticos, ya que para el mundo romano estos constituían, desde la Antigüedad, un medio para mostrar las características de sus sociedades. Respecto a las características del embajador en la antigüedad romana republicana, Buono-Core, 2010; para la época imperial y tardorrepublicana, Torregaray, 2009, pp. 127-133; para Bizancio y el rol de los funcionarios imperiales y su representación, Herrera, 1978, p. 36. 
que actuó el Khan. Cuenta que Mauricio envió como embajadores a Elpidio y Comentiolus solicitando un tratado al Khan, quien actuaba sin moderación en sus crimenes ${ }^{23}$. En este contexto, Comentiolus frente al Khan señaló:

Es apropiado para líderes ser más prudentes que sus súbditos, tanto de hecho como de nombre, de modo que su superioridad en el poder también sea igualada por su distinción en la virtud[...] correspondientemente, debido a su benevolencia pacifica, los romanos ignoran tus enojos previos, se han olvidado de tus numerosos crímenes y, puesto que son distinguidos por muchas naciones por su humanidad, no han movilizado armas en un deseo de represalias. [...] no alardees sobre lo que has arreglado con maldad y ateamente hoy; porque quizás es loable sentirse orgullosos de logros correctos, pero alardear sobre la maldad debe ser designado como arrogancia, y no como gloria. Grandes son sus recientes hazañas de soberbia, pero muy grande también es el poder de los romanos, la diligencia del César, el apoyo de las naciones tributarias, el peso de sus recursos, y su religión, que es la más piadosa de todas las naciones del mundo habitado, y por ello, la más eficaz también ${ }^{24}$

Con el desempeño del embajador Teofilacto otorga una imagen cristiana al Imperio mediante la explicitación de la virtud de la prudencia, así como de las actitudes romanas que denotan el perdón de los actos injustos. A los ávaros, por su parte, los distingue como soberbios y ateos, estableciendo una oposición con los romanos que, apoyados en el cristianismo, otorgan al Imperio Bizantino una condición de fortaleza y confianza en Dios. Como refuerzo a estas ideas, Teofilacto manifiesta que el Khan:

Destruyó la santidad de los embajadores, deshonrando a Comentiolus con cadenas, aplastando sus pies en la mordaza de madera, desgarrando la tienda del embajador $y$, de acuerdo con una costumbre nativa, lo amenazó con la pena de muerte. Al día siguiente de su pasión se calmó, y el más poderoso de los ávaros tranquilizó a su líder con argumentos persuasivos [...a] no pronunciar la pena de muerte [...] el Chagan

23 Teof. Sim., I, 4, 8.

24 Teof. Sim., I, 5, 2-10. 
estuvo de acuerdo, y los envió al emperador en la deshonra ${ }^{25}$.

La caracterización del bárbaro se propone desde la injusticia y la pasión. Se trata de una estrategia narrativa cuyo objetivo es destacar la cristiandad del Imperio, lo que implicaba definirlo mediante situaciones que evocaran un desempeño en coherencia con sus virtudes. Así, no obstante la humillación, Teofilacto señala que el Emperador Mauricio intentó solucionar el conflicto con otra embajada, cuyo pacto implicó el pago de 20.000 monedas de oro ${ }^{26}$, además de las ya 80.000 presupuestadas ${ }^{27}$. A diferencia del episodio previo -que califica de vergonzoso-, en este se destaca el rol del Emperador en la búsqueda de la paz, en un intento por distinguirlo por su prudencia y fortaleza, y demostrar así la condición favorable del Imperio bajo su gobierno ${ }^{28}$.

De este modo, para el primer período del emperador Mauricio, Teofilacto presenta su reinado como fase de triunfos que se definen por mantener la paz. Con todo, para la concepción cristiana de Teofilacto el devenir no resulta indiferente a la Divina Providencia ${ }^{29}$. Esta, interviniendo en la historia, se manifiesta otorgando apoyo o reprobación a los actos de los hombres: $L a$ causalidad activa de la Providencia atraviesa todos los días a todo el mundo, vela por los asuntos mortales con su ojo incansable y siempre administra la retribución de la humanidad por sus actos de violencia ${ }^{30}$.

Precisamente de ese modo ocurre con Bizancio, imperio cristiano apoyado providencialmente en los conflictos, que Teofilacto destaca con énfasis durante el reinado de Mauricio. Cuenta que en la batalla entre Roma-liderada por Filípico- y los persas -guiados por Kardarigan-, ante la desventaja numérica y anímica de los primeros, Filípico Mostró una imagen de Dios Encarnado, que la tradición, desde la antigüedad hasta el presente dí, proclama que fue modelada por la sabiduría divina, y no formada por las manos de un tejedor ni por el pigmento de un pintor ${ }^{31}$.

Quien además, derramando un torrente inagotable de lágrimas por el desperdicio del conflicto, empleó frases de exhortación para el ejército ${ }^{32}$, las

\begin{tabular}{ll}
\hline 25 & Teof. Sim., I, 6, 2-4. \\
26 & Teof., Sim., I, 6, 5-6. \\
27 & Whitby, 2000, p. 41. \\
28 & Sobre la paz en Bizancio, Herrera, 1978, p. 47. \\
29 & Whitby, 2002, p. 319. \\
30 & Teof. Sim., VI, 10, 4-5. \\
31 & Teof. Sim., II, 3, 4-5. \\
32 & Teof. Sim., II, 3, 6. \\
230 &
\end{tabular}


que fueron suficientes para aumentar el esfuerzo [...] y despertar el entusiasmo de indolentes y perezosos ${ }^{33}$.

La exposición de Teofilacto vincula el devenir del Imperio con una causa religiosa cristiana, lo que consigue con la mención de ánimo lograda por Filípico mediante sus palabras y la imagen de Cristo $^{34}$, otorgando así fortaleza sobrenatural a sus logros ${ }^{35}$. Además, la mención refuerza el poderío del Imperio de Mauricio, quien sabiamente habría escogido a Filípico ${ }^{36}$ como general $^{37}$. Teofilacto comenta que el ímpetu de Filípico no habría bastado ante el ejército de Kardarigany puesto que el mal era interminable, advierte que un propósito divino dictó sentencia contra la tribu extranjera [...] donde una voz resonó a toda velocidad entre los romanos, ordenándoles que golpearan en el caballo enemigo $^{38}$. Y hecho esto, los romanos lograron la victoria.

El grito, atribuido al capitán Esteban, fue desmentido por este cuando le preguntaron por la ingeniosidad de la estrategia, advirtiendo públicamente que nunca había producido empresa tan ingeniosa; y era reacio a buscar la gloria de ese modo y falsear las operaciones divinas en su sagacidad personal ${ }^{39}$.

Aunque el evento presenta la interpretación histórica de Teofilacto, constituye, desde el punto de vista historiográfico, un recurso para manifestar un posicionamiento enaltecido del Imperio Romano frente al Persa, dando cuenta del trasfondo cristiano de Bizancio y de la aprobación divina de su desempeño. Esta consideración queda más clara en el enfrentamiento de Comentiolus contra el Khan de los ávaros en el 586, momento en que, frente al agotamiento de las fuerzas romanas: una especie de muerte acuosa vino sobre los bárbaros, en el

$\overline{33}$ Teof. Sim., II, 3, 7.

34 El reforzamiento de la religiosidad del emperador mediante imágenes, íconos y símbolos fue común en el Imperio y no es extraño que Teofilacto utilice el recurso. Whitby, 2000, p. 47.

35 Teof. Sim., II, 3, 8-10.

36 Teofilacto relaciona las actitudes del general y del emperador, definiendo a Filípico como prudente, mesurado y justo, transformándolo en ejemplo moral. Por ej.: Teof. Sim. II, 4, 2-4.

37 Teofilacto destaca el rol de Heraclio, padre del Emperador, como el líder de la facción media del ejército, otorgándole protagonismo (Teof. Sim., II, 3, 2). Aunque mención breve, podría establecer un vínculo a Heraclio y Mauricio; de modo que, para su posterior aparición como como emperador, se presentara en una solución de continuidad.

38 Teof. Sim., II, 4, 7-8.

39 Teof. Sim.,II, 4, 9-10. 
que un reflujo de la marea de repente se tragó al enemigo, por así decirlo ${ }^{40}$.

Se trataría nuevamente de un apoyo divino, cuya interpretación suponía explicitar la intervención sobrenatural para demostrar su apoyo a la causa bizantina. Del mismo modo sucede cuando la Divina Providencia ayuda a los romanos en momentos de hambre, guerra y festividad cristiana:

Con la inminente llegada de la gran fiesta de los cristianos, que celebra por igual la pasión y resurrección de Dios el Salvador, cuando el hambre afectaba duramente a los romanos, el Khan, con extraña providencia, envió a los romanos una embajada cuya misión era poner fin a la hambruna ${ }^{41}$.

Aunque Teofilacto manifiesta la relevancia del reinado de Mauricio, la atmósfera favorable del ambiente no se mantiene de forma homogénea. Antes bien, con el avance de los años el apogeo inicial va sufriendo quiebres, lo que pareciera relacionarse con discrepancias internas de los romanos, como ocurre, a causa de la disminución del estipendio ${ }^{42}$, con la insubordinación del ejército ${ }^{43}$. Para solucionar la situación, el Emperador Mauricio, nombrando a cargo del ejército a Prisco, la enfrentó mediante la diplomacia. Prisco envió a los soldados insubordinados al Prelado de Constantinopla, quien puso al corriente de la normalización del pago a estos últimos ${ }^{44}$. Sin embargo, los soldados, haciendo caso omiso al embajador, lo despacharon, amenazando además la integridad de Prisco $^{45}$.

Para Teofilacto este caso resulta de sumo interés, por cuanto constituye un episodio de insurrección y rechazo a las palabras del clérigo, que, representando el apoyo religioso a la causa imperial, es reprobado por Focas, líder de la facción insubordinada que con posterioridad será fuertemente criticado por el historiador ${ }^{46}$. El evento nos muestra cómo la integración de

\section{0}

41

42

Teof. Sim.,II, 10, 12.

43

Teof. Sim., VII, 13,3-4.

Teof. Sim., p. 36.

a los líderes que llevarían a una anarquía de "gran mal". Si bien no lo explicita en esta ocasión, en otros episodios da cuenta que el líder del grupo insurgente era Focas.

44 Teof. Sim., III, 2, 2-3.

45 Teof. Sim., III, 2, 4-7.

46 Teofilacto califica a Focas como tirano, y se refiere a él indirectamente en 
Focas en la historia se relaciona con situaciones de cariz negativo, donde el apoyo divino deja de manifestarse y adquiere una connotación de decadencia moral que resultará en el debilitamiento del Imperio de Mauricio hasta su muerte.

Así, el cambio anímico se presenta de forma paulatina y la inclusión de otros discursos promueve al Emperador Mauricio sobre los avatares. Un interesante episodio es la guerra interna persa, donde Cosroes, depuesto por el usurpador Baram ${ }^{47}$, acude a Mauricio. Envía a Probo como embajador, quien portando un discurso escrito por el mismo rey depuesto ${ }^{48}$ señala:

Cosroes, rey de los persas, saluda al más prudente rey de los romanos, compasivo, pacifico, magistral, amante de la nobleza y enemigo de la tirania, equitativo, justo, salvador de los heridos, generoso e indulgente [...] hay, pues, ciertos demonios malignos y perversos que abundan en el mundo, que están ansiosos de confundir a todos de las excelentes disposiciones de Dios, y, a pesar de que sus empresas no lo logren, es adecuado a los hombres de Dios, amantes de la piedad, salir al campo contra ellos, después de haber recibido de Dios un tesoro como la sabiduría y el brazo fuerte y armado de la justicia. Ahora, en estos días, los demonios más maliciosos han atacado al Estado persa logrando cosas terribles [...] Baram, ese esclavo abominable [...] ha confundido a todo el estado persa; todo lo que se lleva a cabo y se esfuerza es con el fin de saciar una gran ansia de poder [...] Es entonces apropiado a tu providencia pacifica dar una mano salvadora a un reino ${ }^{49}$.

Varios elementos enaltecen al Emperador Mauricio, a quien Teofilacto define y caracteriza con virtudes y actitudes cristianas que conforman una imagen del Imperio Romano como conjunto. Se establece un directo vínculo entre Roma y el cristianismo que, al plantearse como fundamento del Imperio, legitima la idea de este como sostenedor de la justicia a irradiar por el orbe. Este tipo de discurso se presenta en la segunda etapa anímica de la historia de Mauricio. Allí, los enfrentamientos con otros pueblos conllevan triunfos

episodios que lo rebajan moralmente o que lo relacionan a sedición o destrucción del orden imperial. Véase Diálogo, 4; también VIII, 6, 9; 7,7; 8,1; 10,1; 10,4; 11,1; 13,1; 15,$2 ; 15,8$.

47 Véase Teof. Sim., IV, 9, $1-5$.

48 Teof. Sim., IV, 11, 11.

49 Teof. Sim., IV, 11, 5-8. 
que Teofilacto vincula con el emperador y sus características cristianas, estableciendo una directa relación entre el devenir favorable del imperio y el desempeño de su emperador.

El acontecer favorable, que hemos denominado segunda etapa, decae paulatinamente hasta la muerte de Mauricio y el posterior establecimiento de Focas al poder; donde adquiere una connotación negativa. De modo que a partir de la inclusión de Focas en la historia y especialmente en los episodios de insurrección, el devenir del Imperio comienza una dirección desfavorable en los ámbitos político, militar y espiritual. Esto lo percibimos, por un lado, en los encuentros diplomáticos con ávaros y persas, y, por otro, en la intervención sobrenatural.

A este respecto, Teofilacto ${ }^{50}$ nos cuenta que, con Prisco comandando las fuerzas imperiales en Tracia, el Khan de los ávaros le envió a Koch ${ }^{51}$ como embajador, quien señaló:

¿Qué es esto, oh dioses? Entre aquellos para los que la devoción es apropiada, recientemente se ha establecido la impiedad. Los romanos han roto la paz, han degradado el derecho de los tratados y despreciado las garantías de los acuerdos, el respeto de la confianza se ha desperdiciado, asi como la mediación del juramento, que ha perecido [...] Al hacer la guerra haces el mal; la firma de la paz está agraviada [...] Hacemos la guerra con los dioses de nuestro lado, ya se sitiando la ciudadela de juramentos [...] han dado rienda suelta a traición [...] y los insultos han tomado abiertamente el campo ${ }^{52}$.

El discurso del bárbaro se aleja de los anteriores, e incluso esta vez presenta palabras de sabiduría a los romanos, atendiendo a la violación del acuerdo establecido sobre la movilización de tropas por Tracia ${ }^{53}$. A este respecto, es probable que el mensaje no responda a la época de Mauricio, sino

50 Theo. Sim., VI, 5, 13 - 6, 1.

51 Teof. Sim., VI, 6,6.

52 Teof. Sim., VI, 6, 7-12.

53 La inclusión del discurso es un recurso narrativo de Teofilacto, ya que en otros episodios explica cómo los tratados son violados por los ávaros, producto de su incapacidad para cumplir con la palabra o por su ánimo de poder y dominación territorial $(\mathrm{I}, 8,1)$. La mención destaca las palabras de los bárbaros para evidenciar los problemas e incoherencias internas de Roma, y, además, el perdón que luego otorgará Prisco al atrevimiento. 
a la del propio autor de la Historia $^{54}$, que dirigiéndose a un público romano ${ }^{55}$ pudo evidenciar el decaimiento político-jurídico -y moral- de Roma por la caída del Emperador Mauricio y por el interés de Focas por el poder. Con todo, la crítica es paulatina antes de la muerte de Mauricio; y mientras gobernó, Teofilacto manifiesta sus esfuerzos por dirigir el imperio. Así, para contrarrestar las palabras del bárbaro y aminorar la visión negativa de Bizancio en tiempos de Mauricio, advierte: Después del término de este discurso, y a pesar de la angustia suscitada por la fuerza y dirección de las palabras, Prisco concedió el perdón a la audacia del bárbaro. Por lo tanto, no ofreció ninguna refutación a la temeridad ${ }^{56}$.

En el episodio podemos identificar la actitud cristiana de Prisco a partir del perdón ${ }^{57}$, lo que se refuerza con manifestaciones a la prudencia y mesura con que trató una situación que bien podría haber suscitado disputas mayores. Asimismo sucede en otra intervención romana frente al Khan de los ávaros ${ }^{58}$, donde Teodoro, embajador romano, entrega un mensaje que expresa por última vez bajo el reinado de Mauricio palabras de sabiduría, que exhiben al Imperio Romano como prudente, justo y mesurado. Cuenta Teofilacto ${ }^{59}$ que ante la grandilocuencia y soberbia del bárbaro, quien señaló al embajador su inmensa propiedad y la inexistencia de quien lo enfrentara ${ }^{60}$, el romano, cuya comprensión de la historia era genial, humilló la grandilocuencia del bárbaro con precedentes $^{61}$, diciendo:

Escucha, Changa, un cuento antiguo y muy sabio. Dicen que una vez vivió un hombre: Sesos tris, que era muy afortunado y el más eminente en el reino de Egipto. La antigua leyenda dice que este hombre se enorgullecía de su riqueza y de que sus fuerzas fueran completamente invencibles ${ }^{62}$. Pero se embruteció tanto, por así decirlo, que construyó

\begin{tabular}{ll}
\hline 54 & Véase Scott, 2010, pp. 252-253. \\
55 & Rohrbacher, 2002, p. 159. \\
56 & Teof. Sim., VI, 6, 13-14. \\
57 & Teof. Sim., VI , , 13. \\
58 & Teof. Sim., VI, 11, 7. \\
59 & Teof. Sim., VI, 11, 10. \\
60 & Teof. Sim., VI, 11, 9. \\
61 & Teof. Sim., VI, 11, 9.
\end{tabular}

62 De acuerdo a Whitby, Menandro señala que la historia en cuestión fue usada con un propósito similar por el Patricio Pedro durante las negociaciones con los persas el 561 (Véase Whitby, 1986, p. 212, nota 67), lo que podría indicar que Teofilacto 
un carro de oro con incrustaciones, envuelto con piedras preciosas, y se sentó en él; se despidió de yeguas y de mulas, pero con el yugo rodeó los cuello de los reyes conquistados, y estos, desafortunados, sacaron el carro de Sesos tris al foro. Entonces el rey de Egipto no se comportó moderadamente con su victoria, sino que con frecuencia reprochó su derrota con desgracia. Dicen que en un grande y famoso festival, cuando las multitudes de egipcios se habian congregado, uno de los reyes sometidos a la carroza-yugo no sacó el carro y, echándose hacia atrás en repetidas ocasiones, observó el movimiento de las ruedas. A continuación, el transporte se volvió inarmónico, ya que los designados para este propósito no actuaban de común acuerdo, y el rey de Egipto dijo al que se retorcía en repetidas ocasiones: "Hombre, ¿por qué estás cambiando tu mirada hacia atrás? ¿Por qué estás examinando las ruedas? ¿Qué esperas lograr con la boca abierta?" Pero él, con gran inteligencia, dijo a Sesostris: "me he maravillado por el movimiento de las ruedas. Tienen un movimiento inconstante: Ahora, partes de ellas en el aire vuelven de nuevo a la tierra, mientras que de nuevo las partes de la planta son elevadas" Por lo cual Sesos tris, dicen, al oír esto, aprendió a no ser arrogante, y decretó que los cuellos reales fueran liberados de los yugos, y que a partir de entonces el transporte de mercancías se confiara a las mulas. Que esta sea la lección, Chagan. Nada es menos fiable que el éxito ${ }^{63}$.

En el discurso de Teodoro destacan la prudencia y la mesura, cuyo objetivo persigue, a ojos del autor, la justicia de los eventos. En este marco, el discurso se plantea en coherencia con la idea de un imperio cuyo fin trasciende la individualidad del gobernante, otorgando una relación con las virtudes y actitudes cristianas que a lo largo del escrito pretenden caracterizar al Imperio Bizantino. Asimismo, y considerando al público de la Historia, el texto no solo nos remite a un discurso dirigido al Khan, sino que la situación explicada por el embajador bien puede constituir una analogía entre las actitudes de Sesostis en Egipto y las de la misma Roma de la época de Focas ${ }^{64}$. De este modo, el texto

conocía la obra, y explicar que la visión que promueve en su Historia respondió a su propia época. Esto nos permite aproximarnos a los propósitos de Teofilacto, que se habrían dirigido a forjar la imagen cristiana del imperio en función de las necesidades y problemas de su tiempo.

63 Teof. Sim., VI, 11, 10-15.

64 Scott, R., 2010, p. 153. 
podría instaurarse como refuerzo en la construcción de una imagen negativa de Focas como gobernante.

Resulta de interés la paulatina integración de aspectos sobrenaturales que manifiestan un decaimiento del imperio de Mauricio, así como la presentación de malos augurios que manifiestan un futuro desfavorable. Comenta que previo al envío de Teodoro, en el mismo período de guerra contra los ávaros:

Prodigios extraños nacieron en las proximidades de la ciudad: un niño de cuatro patas y otro con dos cabezas. Aquellos que se han involucrado profundamente con estas historias dicen que la aparición de portentos en ciudades no significa nada bueno. Y así, los prodigios fueron exhibidos al emperador Mauricio y condenados a muerte ${ }^{65}$.

Las menciones sobrenaturales también constituyen un recurso narrativo para entregar ánimo al relato. En este marco, ya avanzada la narración, y cuando Focas se ha integrado en el acontecer -principalmente como embajador de los insurrectos-, nos cuenta Teofilacto:

En el curso del decimonoveno año del gobierno del emperador, una predicción de futuro ocurrió y reconoció los sufrimientos universales del mundo; para un cierto hombre, que se había retirado del mundo actual, que había participado de los misterios a través de la práctica de la contemplación y que se retiró a una vida solitaria, luego de haber desenvainado una hoja y de pasearse por el Foro con ella en la mano [...] profetizó que el emperador, junto con sus hijos, morirían asesinados por el cuchillo [...] El hombre aseveró que el mensaje profético se había manifestado a él, no sin expresión divina ${ }^{66}$.

La predicción manifiesta por el anacoreta se cumpliría a cabalidad el año 602 bajo las órdenes de Focas, y los males que ello acarreó traerían, al decir de Teofilacto, los sufrimientos del mundo. La inclusión de la profecía en la Historia no es resultado de una actitud inocente o imparcial del historiador, sino todo lo contrario; la mención de los sufrimientos universales y de la muerte de

65 Teof. Sim. VI, 11, 1.

66 Teof. Sim., VII, 12, 10-11. 
Mauricio ${ }^{67}$ son un recurso para demostrar que el responsable de ello es Focas ${ }^{68}$, de quien Teofilacto construye una imagen negativa. Esto lo entendemos mejor si consideramos que Simocatta construye un relato que pretende exaltar el reinado de Mauricio y vincularlo con el de Heraclio por su proyecto cristiano común ${ }^{69}$, cuya mención, aunque de modo implícito, nos la entrega en la sección más original de su composición, esto es, el diálogo entre la Filosofía y la Historia, narración "sin paralelo en la historiografía clásica o cristiana"70.

\section{Del discurso diplomático al discurso inaugural: el diálogo entre Filosofía e Historia}

Si bien los casos analizados se presentan como ejemplos para instalar ideas favorables a Mauricio y contrarias a Focas, donde los discursos de la diplomacia y las intervenciones sobrenaturales constituyen un modo de presentar, contextualizar y reforzar el ideario de Teofilacto, otros aspectos dan cuenta de las intenciones del autor por integrar a Heraclio en el relato, así como de otorgarle una connotación favorable a su reinado. Se trata de discursos presentes al inicio del escrito, cuyo propósito es evidenciar el resurgimiento de la historia, que, según Teofilacto, estuvo largo tiempo muerta ${ }^{71}$.

El diálogo entre la Filosofía y la Historia comienza con una mención de la Filosofía solicitando ayuda a la Historia para solucionar los dilemas del conocimiento en la investigación ${ }^{72}$, a lo que la última responde, con humildad, que la ayudará en lo que alcanzara su entendimiento, advirtiendo luego: nada justo puedo mantener en desconocimiento ${ }^{73}$. A través de esta mención, Teofilacto manifiesta la validez y la necesidad de la historia, lo que colabora a

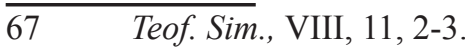

68 Teof. Sim., VIII, 11, 1.

69 Teofilacto nos señala que al inicio del reinado de Heraclio se encontró una carta con las disposiciones de Mauricio antes de su muerte. Si bien no se ahonda en su contenido, la mención constituye un tipo de legado entre ambos emperadores. Véase Teof. Sim., VIII, 11, 7.

70 Whitby, 1986, p. 40.

71 Sobre el diálogo inaugural, Whitby advierte que después de la muerte de Focas la Filosofía había resurgido gracias al patronazgo de Heraclio a Stephen, y la historia mediante el apoyo del Patriarca Sergio a Teofilacto. Se trataría de un recurso literario para exaltar al Patriarca. No obstante, dentro del marco general de la Historia, el diálogo contribuye en la ambientación, toda vez que el resurgimiento de la historia se habría logrado en el reinado del emperador que depuso a Focas. Véase Ibid., p. 40.

72 Teof. Sim. Diálogo, 1.

73 Teof. Sim. Diálogo, 2. 
legitimar su relato y a disponer la atención de su receptor. Y luego introduce una exposición de la Filosofía a la Historia que nos remite a su propia época y que permite comprender un mensaje que promueve la visión favorable de Heraclio y que denosta la de Focas. Apunta Teofilacto:

Filosofía: Con alegría te preguntaría, hija mía, por qué medios y cómo fue que solo el otro día tú volviste a la vida. Pero la gran seducción de nuestra incredulidad nos comprueba el discurso nuevamente y, como si fuera un bozal, nos restringe al silencio, no sea que por ventura de una aparición maravillosa nos esté seduciendo. Porque, mi niña, tú estabas muerta hace mucho tiempo [...] Voy a guardar silencio sobre el resto, por respeto a mi propio decoro y la dignidad de la audiencia. Yo también, hija mía, fui condenada al ostracismo después de la columnata real, y no podía entrar al Ática en el momento en que Tracio Anito destruyó a Sócrates mi rey. Pero, posteriormente, el Heráclida salva y restaura el estado, exorciza la polución de los palacios, y de hecho se instaló en el recinto real. Celebro a las cortes reales y compongo estos antiguos himnos áticos para mí; de hecho, esta es la fuente de la prosperidad; pero para usted, mi hija, quien fue tu salvador y como fuiste salvada?

El caso resulta de interés, ya que Teofilacto da cuenta que la historia no ha podido escribirse en el período de Focas, constituyendo una afrenta al conocimiento de lo justo. Sin embargo, la intervención de la Filosofía, señalando su situación similar en tiempos de Ánito, representa una analogía para comprender el carácter que intenta otorgarle a Focas ${ }^{74}$, a quien relaciona al antiguo acusador de Sócrates, que Aristóteles ${ }^{75}$ conecta con las prácticas del soborno a los tribunales atenienses y quesería acusado por traición a la patria ${ }^{76}$. Por otra parte, la Filosofía alude a los heráclidas y concede un papel ordenador a Heraclio ${ }^{77}$, como restaurador o fundador de Bizancio.

El diálogo entre Historia y Filosofía permite identificar que el escrito se refiere al pasado desde el tiempo del autor ${ }^{78}$, puesto que "elabora una retórica

$74 \quad$ Whitby, M., 2002, p. 30, nota 6.

$75 \quad$ Constitución de los atenienses, 27, 5.

$76 \quad$ Véase García, 1984, p. 121, nota 237.

77 Whitby, 2002, p. 30, nota 7.

78 Frendo, 1988, p. 153 ss. 
que está en directa relación con los hechos relevantes de su época”. Así, la intervención providencial responde a la cultura bizantina de su época ${ }^{79}$. A este respecto, Marín advierte situaciones similares a las de Teofilacto en otros textos del período, que recogiendo los sucesos del sitio de los ávaros a Constantinopla, dan cuenta de interpretaciones de la historia similares. En este sentido, el sitio ávaro del 626 implicó "la confirmación de sus creencias - y quizá también de sus temores- y su confianza en la Divina Providencia. En efecto, los habitantes de la Basilévusa Pólis pudieron apreciar con sus propios ojos cómo la ciudad era salvada por un milagro: la Virgen María, intercesora predilecta ante su Hijo Jesucristo, se manifestó como generala invicta y defensora de sus devotos fieles" $"$. Se trata de un episodio conmemorado "en textos laudatorios y religiosos"81, donde la intervención de la Virgen María no podía sino reafirmar el apoyo divino a la causa cristiana. De modo que si esto ocurrió en tiempos de Heraclio, donde Teofilacto escribió su Historia, no es difícil imaginar que su proyecto imperial se relacionara directamente con el apoyo providencial, pues luego de la decadencia romana en época de Focas, "uno de los modelos para contrarrestar los sentimientos negativos y restaurar la ideología del emperador y el imperio fue otorgar a la victoria de Heraclio un rol positivo y significación universal, dentro del marco de escatología imperial" "82. Desde esta perspectiva, la continuidad planteada por el texto entre Mauricio y Heraclio debemos entenderla como una exaltación de conductas a imitar por los bizantinos que, al escuchar la narración, confirmarían sus creencias sobre el Imperio Romano en su perspectiva escatológica.

\section{Del propósito del texto}

Finalmente, creemos que el Proemio entrega algunos datos sobre lo que creemos es el fin último de su historia: proponer ejemplos morales y cristianos mediante una historia que, a través de su declamación ${ }^{83}$, fuera asimilada por la corte bizantina. Y ello porque en el Proemio Teofilacto nos señala tres aspectos que nos parecen decidores para comprender la narración. El primero es el reconocimiento universal de la historia; el segundo es el carácter educativo del

79 Croke, 2007, p. 572, que adviértela "unidad" entre la Historia de Teofilacto y el Chronicon Pascale, respondiendo ambas a los eventos y concepciones religiosas y políticas de la época.

80 Marín, J. 2011, p. 42.

81 Idem.

82 Reinink, 2002, p. 83.

83 Frendo, J. 1988, p. 147. 
texto, idea común en el mundo clásico y también cristiano; y el tercero es su connotación declamatoria. A este respecto, Teofilacto nos menciona: Y lo más notable de todo, se ha establecido la amplia experiencia de la historia, una delicia para el oído, pero la educación para el alma; para las almas ansiosas de aprender, no hay nada más seductor que la historia ${ }^{84}$.

El texto presenta la Historia en coherencia a los modelos clásicos y cristiano, esto es, bajo una perspectiva de maestra de vida ${ }^{85}$; sin embargo, la mención como delicia para el oído nos remite a la lectura de la misma frente a un público $^{86}$, lo que nos permite comprender, por un lado, la expresividad y estilo que Teofilacto concede a la narración y, por otro, el modo en que los discursos, emitidos cual obra teatral, pudieron constituir un recurso para establecer la visión y ánimo que se propuso conceder al Imperio y a sus emperadores. En este marco, "la oralidad propia de la cultura medieval, en la cual no solo se lee sino que se escucha, queda de manifiesto cuando el autor se dirige no solo al

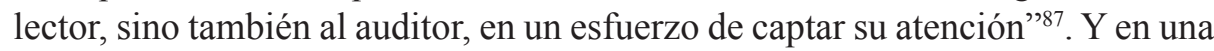
línea similar, el historiador continúa:

Se debe considerar a la historia común de toda la humanidad como una maestra, que asesora sobre lo que debería de llevarse a cabo, y sobre lo desventajoso que debería de ser ignorado. Se puede observar que los grandes generales son más prudentes por medio de ella [...] hace que estos hombres sean más providentes, guiándolos a través de los errores anteriores de otros [...] por los éxitos los hace más afortunados, causando grandes niveles de virtud a partir de pequeños comienzos $^{88}$.

Nuestro autor pone énfasis en una historia universal que permita guiar en lo ventajoso y virtuoso, planteando la labor bizantina sobre el orbe bajo una concepción totalizante y ecuménica. En otras palabras, el Proemio intenta disponer a quien lea o escuche de modo tal que no solo entienda lo acontecido, sino también a dejarse persuadir por el historiador ${ }^{89}$.

\begin{tabular}{ll}
\hline 84 & Teof. Sim. Proemio, 6. \\
85 & Véase Rohrbacher, 2002, p. 151. \\
86 & Ibid., p. 159. \\
87 & Marín, J, 2014, p. 534. \\
88 & Teof. Sim.,Proemio, 13-15. \\
89 & Rohrbacher, D., 2002., p. 150.
\end{tabular}


Si bien es esta una característica que podría denotar desde el prólogo un fin propagandístico o panegírico hacia Heraclio ${ }^{90}$, nos parece que este nos permite ir más allá, puesto que "a pesar de su brevedad y concisión, dichos para textos se constituyen en utilísimos instrumentos para ponderar la idea de la historia que subyace en ellos y que además es patrimonio de la sociedad en que se insertan y de la que se desprenden"91. En este sentido, aunque el resultado final de la Historia evidencie un claro interés por entregar a Mauricio una posición favorable, nos parece que no es producto de un propósito solo político o personalista. Antes bien, es resultado de un modo de entender el devenir por Teofilacto que, inmerso en una sociedad de profunda raigambre cristiana y además enfrentada a situaciones que produjeron interpretaciones sobrenaturales, vio la necesidad de fortalecer la idea de un Imperio centrado en lo cristiano y universal, donde el apoyo divino respaldara un proyecto espiritual.

De este modo, los discursos sobre la diplomacia, las referencias a los emperadores, las etapas anímicas del relato y las intervenciones sobrenaturales son recursos narrativos, pero también realidades de su cultura que probablemente animaron a Teofilacto a escribir una historia que constituye, a nuestro parecer, buena prueba del modo de entender el devenir en el Imperio Romano del siglo VII.

\section{Conclusiones}

1. La Historia de Teofilacto Simocatta ofrece un relato que construye una imagen del Imperio Romano en directa relación con virtudes y actitudes cristianas. Para ello, se recurre a discursos diplomáticos, atmósfera anímica e intervención providencial.

2. A lo largo del escrito, los emperadores Mauricio y Heraclio tienden a relacionarse como parte de un proyecto cristiano común, lo que se acompaña de la denostación de Focas, a quien se caracteriza como tirano.

3. El Diálogo inicial, el Prólogo y la inclusión de amplios discursos, permiten entrever que la obra fue ordenada para ser declamada en público, por lo que los episodios destacados se proponen de manera expresiva. Estos, a nuestro parecer, pretenden instar al lector a reflexionar sobre el proyecto cristiano de los emperadores Mauricio y Heraclio, para así, desde su propia época, comprender el reinado de Heraclio como parte de un proyecto cristiano correcto a la perspectiva escatológica de la época; donde Roma, predestinada por Dios para

\begin{tabular}{ll}
\hline 90 & Frendo, 1988, p. 149. \\
91 & Marín, J., 2014, p. 532. \\
242 &
\end{tabular}


liderar el cristianismo hasta el fin de los tiempos, debía actuar en conformidad al bien.

4. Concebida desde una dimensión educativa, en la Historia se proponen ejemplos que denotan el correcto desempeño cristiano, representado, principalmente, en el Emperador Mauricio en la primera etapa de su gobierno. Allí, los episodios diplomáticos se transforman en recursos para evidenciar la perspectiva de Teofilacto, toda vez que, mediante representantes, se enfrentan pueblos diversos, donde el Imperio Bizantino se propone como ejemplo de prudencia y de justicia.

5. En la historia, si bien la inclusión de episodios de intervenciones providenciales y sobrenaturales constituyen recursos narrativos al propósito de Teofilacto, estos trascienden el escrito, pues connotan una interpretación común de su época, dando cuenta que la obra forma parte de un contexto de concepción escatológica y providencialista. En este sentido, la Historia, como testimonio de su tiempo, no necesariamente nos remite la época de Mauricio, sino más bien a la época en que fue escrita, esto es, el reino de Heraclio.

\section{REFERENCIAS BIBLIOGRAFICAS}

ARISTÓTELES. (1984). Constitución de los atenienses. Trad. de Manuel García. Madrid: Gredos.

AURELL, J. (2006). "El nuevo medievalismo y la interpretación de los textos históricos", Hispania, LXVI, 224.

BALMACEDA, C. (2013). "La Antigüedad tardía: la historiografía cristiana y bizantina". Aurell, J.; Balmaceda, C.; Burke, P. y Soza, F. Comprender el pasado. Una historia de la escritura y el pensamiento histórico, Madrid: Akal.

BARTHES, R. (1977). "Introducción al análisis estructural de los relatos", Niccolini, S. (comp.). Análisis estructural. Buenos Aires: Centro Editor de América Latina.

BLOCKLEY, R. (1985). "Subsidies and Diplomacy: Rome and Persia in late Antiquity", Phoenix, 39, 1.

BUONO-CORE, R. (2010). "Diplomacia romana: una diplomacia moderna?", Anabases, 12.

CHRYSOS, E. (2005). "La guerra y la paz en la política y en el pensamiento de los bizantinos", Cuadernos del CEM y R, 13.

CROKE, B. (2007). "Late Antique Historiography, 250-650 CE”, John Marincola (ed.). A Companion to Greek and Roman Historiography, I. Reino Unido: Blackwell Publishing. 
FRENDO, J. (1988). "History and Panegyric in the Age of Heraclius: The Literary Background to the Composition of the "Histories" of Theophylact Simocatta", Dumbarton Oaks Papers, 42.

REININK, G. (2002). "Heraclius, the New Alexander. Apocaliptic Prophecies during the Reign of Heraclius", Reinink, G. y Bernand, S. (eds.), The Reign of Heraclius (610-641). Crisis and Confrontation, III. Louven-Paris-Dudley: Peeters.

HERRERA, H. (1972). Las relaciones internacionales del Imperio Bizantino en la época de las grandes invasiones. Chile: Centro de estudios Bizantinos y Neohelénicos de la Universidad de Chile.

KAEGY, W. (2003). Heralius Emperor of Byzantium, Reino Unido: Cambridge University Press.

LIEBESCHUETZ, W. (2003). "Pagan Historiography and the Decline of the Empire", Gabriele Marasco (ed.), Greek and Roman Historiography in Late Antiquity. Leiden-Boston: Brill.

MARÍN, J. (2011). "Bizancio en el siglo VII: entre historia y profecía. Notas en torno a los sucesos del año 626", Byzanthion Nea Hellas, 30.

MARÍN, J. (2014). "El prólogo como género específico en obras históricas (siglos IVVIII), Studi Medievali, Serie Terza, Anno LV, Facs. II.

SCOTT, R. (2010). "Text and Context in the Byzantine Historiography". James, L. (ed.), A companion to Byzantium. Reino Unido: Blackwell Publishing.

SIGNES CODOÑER, J. (2003). "La historiografía en el oriente del Imperio Romano desde el Saco de Roma por Alarico hasta las invasiones árabes", Cuadernos de literatura griega y latina, 4 .

TORREGARAY, E. (2009). "Legatorum Facta: La ejemplaridad de los embajadores romanos", Veleia, 26.

WHITBY, MICHAEL Y WHITBY, MARY. (1986). The History of Theophylact Simocatta.Nueva York: Oxford University Press.

WHITBY, M. (2000). “The successors of Justinian”, Cambridge Ancient History, XIV.

WHITBY, M. (2002). The Emperor Maurice and His Historian. Nueva York: Oxford University Press. 